\title{
Increased incidence of subarachnoid hemorrhage during cold temperatures and influenza epidemics
}

\author{
Daan Backes, MD, ${ }^{1}$ Gabriel J. E. Rinkel, MD, FRCPE, ${ }^{1}$ Ale Algra, MD, PhD, ${ }^{1,2}$ llonca Vaartjes, PhD, ${ }^{2}$ \\ Gé A. Donker, MD, PhD, ${ }^{3}$ and Mervyn D. I. Vergouwen, MD, PhD ${ }^{1}$
}

${ }^{1}$ Department of Neurology and Neurosurgery, Brain Centre Rudolf Magnus, and 2Julius Center for Health Sciences and Primary Care, University Medical Center Utrecht; and ${ }^{3}$ Netherlands Institute for Health Services Research, Utrecht, The Netherlands

\begin{abstract}
OBJECTIVE This study investigated whether the increased incidence of aneurysmal subarachnoid hemorrhage (SAH) in winter is related to temperature or increased incidence of influenza. Such relationships may elucidate the pathogenesis of intracranial aneurysm rupture.

METHODS A nationwide sample of 18,714 patients with SAH was linked with weekly temperature and influenza-like illness consultation data. Poisson regression analyses were used to calculate incidence density ratios (IDRs) with corresponding $95 \% \mathrm{Cls}$ for the association of SAH incidence with temperature and influenza epidemics; IDRs were adjusted for study year (alDR). In addition, SAH incidence data from 30 European population-based studies were linked with daily temperature data from the European Climate Assessment.
\end{abstract}

RESULTS The aIDR for SAH during influenza epidemics was $1.061(95 \% \mathrm{Cl} 1.022-1.101)$ in the univariable and 1.030 $(95 \% \mathrm{Cl} 0.989-1.074)$ in the multivariable analysis. This association declined gradually during the weeks after epidemics. Per $1^{\circ} \mathrm{C}$ temperature drop, the alDR was $1.005(95 \% \mathrm{Cl} 1.003-1.008)$ in the univariable and $1.004(95 \% \mathrm{Cl} 1.002-1.007)$ in the multivariable analysis. In the European population-based studies, the IDR was $1.143(95 \% \mathrm{Cl} 1.129-1.157)$ per $1^{\circ} \mathrm{C}$ temperature drop.

CONCLUSIONS The incidence of SAH is increased during cold temperatures and epidemic influenza. Future studies with individual patient data are needed to investigate causality between temperature or influenza and SAH.

http://thejns.org/doi/abs/10.3171/2015.8.JNS151473

KEY WORDS incidence; inflammation; influenza; intracranial aneurysm; subarachnoid hemorrhage; season; vascular disorders

$\mathrm{T}$ HE incidence of aneurysmal subarachnoid hemorrhage $(\mathrm{SAH})$ varies during the year, with higher incidences in winter than in summer, and a peak in January. ${ }^{10,13,15}$ The underlying cause for this seasonal variation remains uncertain but may shed some light on the pathogenesis of intracranial aneurysm rupture. Meteorological factors such as temperature, humidity, and atmospheric pressure have been suggested as underlying causes in studies from many different countries, but the data are inconsistent. ${ }^{10}$ Other studies hypothesized that infections such as influenza may contribute to the increased incidence of SAH during winter, but the reported associations were conflicting. ${ }^{14,24,30,52,58}$ These inconsistencies may be due to the small number of included patients, resulting in low precision. Moreover, most studies that investigated associations between meteorological factors or infections and SAH incidence were single-center or regional studies, which may have been subject to selection or referral bias. Therefore, we conducted a large nationwide study with additional analysis of SAH incidence data from $\mathrm{Eu}-$ ropean population-based studies to investigate the association between influenza epidemics or temperature and the incidence of SAH.

\section{Methods \\ Data Sources}

Approval for this study was obtained from the Institutional Research Ethics Board of the University Medical Center Utrecht, the Netherlands. For the purpose

ABBREVIATIONS CDR = Cause of Death Register; ECA = European Climate Assessment; HDR = Hospital Discharge Register; ICD = International Classification of Diseases; IDR = incidence density ratio; NIVEL = Netherlands Institute for Health Services Research; SAH = subarachnoid hemorrhage

SUBMITTED June 24, 2015. ACCEPTED August 20, 2015.

INCLUDE WHEN CITING Published online January 29, 2016; DOI: 10.3171/2015.8.JNS151473. 
of this study, we used 4 databases: 1) a nationwide cohort of patients with SAH registered by Statistics Netherlands (http://www.cbs.nl); 2) prospectively collected influenza consultation data registered by the sentinel general practices of the Netherlands Institute for Health Services Research (NIVEL) Primary Care Database (www.nivel. nl/peilstations); 3) European data on daily temperature collected by the European Climate Assessment (ECA), including daily temperature data measured at the weather station of the Royal Netherlands Meteorological Institute in the Bilt, Utrecht, the Netherlands; ${ }^{28}$ and 4) data on $\mathrm{SAH}$ incidence in Europe with emphasis on geographical region, which were collected in a systematic review. ${ }^{9}$

\section{Dutch SAH Cohort}

This nationwide cohort was constructed by Statistics Netherlands with information from the national Hospital Discharge Register (HDR) and the Cause of Death Register (CDR), and includes all SAH admissions and deaths between October 1995 and October 2010, thereby covering a population of approximately 16 million inhabitants. These registries have been described and validated in previous studies, which showed that the diagnosis of nontraumatic SAH was accurate in more than $95 \%$ of the cases. ${ }^{37,38,55} \mathrm{In}$ summary, for each hospital admission a new record was created in the HDR, including information regarding age, admission date, and principal diagnosis on admission. The principal diagnosis was determined at discharge and was coded with the WHO International Classification of Diseases, Ninth Revision (ICD-9). The CDR holds records of the underlying and contributing causes, place, and date of death for all Dutch citizens, and is coded with the 10th revision of the ICD (http://www.who.int/classifications/icd/ en/). All hospital admissions for SAH (ICD-9 code 430) and all out-of-hospital mortality records with SAH as the underlying cause of death (ICD-10 code I60) between 1995 and 2010 were selected from the HDR and CDR.

\section{Dutch Influenza-Like Illness Cohort}

The NIVEL (www.nivel.nl/peilstations) uses a network of general practitioners throughout the Netherlands that covers $0.7 \%-1 \%$ of the Dutch population. It is representative of the entire Dutch population with regard to age, sex, regional distribution, and degree of urbanization. The NIVEL influenza-like illness cohort includes all patients who presented to the general practitioner in sentinel general practices with influenza-like illness, which is defined as an illness with an acute onset (prodromal stage $\leq 4$ days), fever (defined as a rectal temperature $\geq 38^{\circ} \mathrm{C}$ ), and $\geq 1$ of the following symptoms: cough, nasal catarrh, sore throat, frontal headache, retrosternal pain, or myalgia. The incidence of influenza-like illness per week was calculated by dividing the total number of influenza-like illness consultations per week by the total number of citizens in the corresponding sentinel general practices coverage area. According to our national influenza surveillance program, an influenza epidemic was defined as an incidence of influenza-like illness $>51 / 100,000$ citizens during 2 consecutive weeks, and if nose and throat swabs from these weeks were found to contain influenza viruses (www.nivel.nl/peilstations). We used influenza-like illness consultation data between 1995 and 2010, which were stratified per week according to the International Organization for Standardization 8601 standard (http://www. iso.org).

\section{Temperature Data}

The ECA collects daily meteorological data from more than 10,000 meteorological stations situated in 62 countries throughout Europe and the Mediterranean. ${ }^{28}$ The reliability of the ECA data set has been validated with the nearest meteorological land-grid boxes, with a correlation coefficient of 0.8 for $93 \%$ of the daily temperature series. ${ }^{28}$

\section{European SAH Incidence Data}

We used data on SAH incidence with emphasis on geographical region from a systematic review, which included all population-based studies on SAH incidence published between 1960 and 2005. ${ }^{9}$ The methods of literature search, inclusion criteria for studies, and diagnostic criteria for SAH have been described in the original publication. ${ }^{9}$ For this study, we included data on SAH incidence from all included population-based studies performed in European countries.

\section{Statistical Analysis}

In the Dutch SAH cohort, the day of admission was used to stratify the total number of SAH events per week. Influenza epidemics were dichotomized (present or absent) for further statistical analysis. Because the influenza season runs from October to May of the following year, influenza epidemics may cross the calendar year (www. nivel.nl/peilstations). For this reason, a study year was defined from the week of October 1 until the week of October 1 the following year.

First, we performed nationwide analyses with data from the Dutch SAH cohort, influenza-like illness data, and Dutch temperature data. The incidence of SAH during influenza epidemics was compared with the incidence in times without influenza epidemics, by calculating incidence density ratios (IDRs) with corresponding 95\% CIs using univariable Poisson regression analyses. In addition, we performed time-window shift analysis up to 8 weeks after the start of the epidemic to investigate if there was a delay between onset of the influenza epidemic and the incidence of SAH (Fig. 1). Subsequently, we used mean weekly temperatures measured at the weather station of the Royal Netherlands Meteorological Institute in the Bilt, Utrecht, the Netherlands, to calculate the IDR with corresponding $95 \% \mathrm{CI}$ for $\mathrm{SAH}$ per $1{ }^{\circ} \mathrm{C}$ drop in temperature, using univariable Poisson regression analysis. ${ }^{28}$ Then, mean weekly temperature and the presence of influenza epidemics (present or absent) were entered into a multivariable Poisson regression analysis to calculate the IDRs with corresponding 95\% CIs for SAH as outcome. All analyses were repeated with adjustment for study year.

Second, we analyzed the association between temperature and SAH incidence. We used 1) SAH incidence data from European population-based studies and 2) mean dai- 


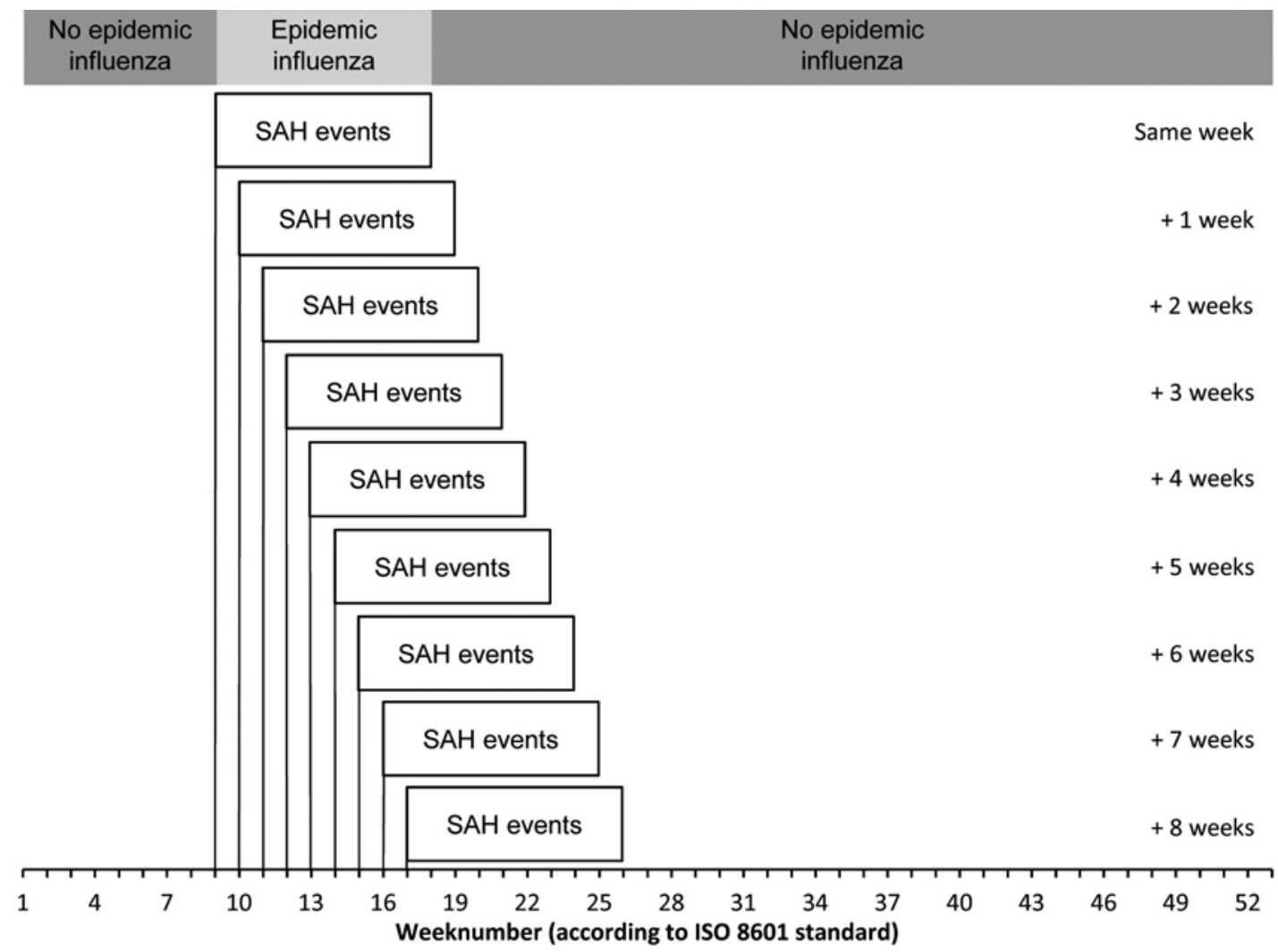

FIG. 1. Schematic illustration of the time frame shift analyses. The number of SAH events that occurred within 1-8 successive weeks after the start of the epidemic influenza was used in additional analysis to investigate whether there was a delayed association of epidemic influenza with the incidence of SAH. ISO = International Organization for Standardization.

ly temperature data (from weather stations closest to the corresponding geographical region in which the SAH incidence study was performed) from the ECA database to calculate the IDR and corresponding 95\% CI for SAH for each $1^{\circ} \mathrm{C}$ drop in temperature..$^{9,28}$ The mean temperature during the study period of each population-based study was calculated by the average of all mean daily temperatures during the study period. Missing mean daily temperature values were imputed by using the average of the mean daily temperature values of adjacent days.

\section{Results}

\section{Influenza Epidemics and SAH in the Netherlands}

A total of 18,714 SAH events were registered in the Netherlands between October 1995 and October 2010, with a mean of 1248 events per study year (SD \pm 63 ). During the study period, there was a total of 34,404 influenzalike illness consultations at the sentinel practices, with a mean of 2294 consultations per study year $(S D \pm 851)$. Extrapolated to the whole country, this would have been 3.4-4.9 million consultations. The mean incidence of influenza-like illness and the mean number of SAH events per week during the study period, including $95 \% \mathrm{CI}$ and regression trend lines, are shown in Fig. 2. The mean incidence of influenza-like illness was $1809 / 100,000$ per study year $(\mathrm{SD} \pm 570)$. The median duration of epidemic influenza per study year was 9 weeks (range 3-16 weeks), with the beginning of the influenza epidemics varying from early October to the end of February. The IDRs for the association between SAH and epidemic influenza are shown in Table 1. The IDR of SAH during epidemic influenza was 1.047 (95\% CI 1.009-1.087), and after adjustment for study year it was 1.061 (95\% CI 1.022-1.101). In the analyses in which the incidence of SAH was analyzed 1-8 successive weeks after an influenza epidemic, there was a gradual decline of the IDR during the weeks following the start of an epidemic.

\section{Mean Weekly Temperature and SAH in the Netherlands}

The mean weekly temperature measured at the weather station of the Royal Netherlands Meteorological Institute in the Bilt, Utrecht, the Netherlands between October 1995 and October 2010 was $10.5^{\circ} \mathrm{C}$ (range $-7.4^{\circ}-24.5^{\circ} \mathrm{C}$ ). The mean weekly temperature and the mean number of SAH events per week during the study period, including 95\% CI and regression trend lines, are shown in Fig. 3. The IDR for the association between $\mathrm{SAH}$ and $1{ }^{\circ} \mathrm{C}$ drop in mean weekly temperature was 1.004 (95\% CI $1.002-1.007)$, and after adjustment for study year it was 1.005 (95\% CI 1.003-1.008) (Table 1).

\section{Influenza Epidemics, Mean Weekly Temperature, and SAH in the Netherlands}

The IDRs of the multivariable Poisson regression analyses for the associations among SAH, mean weekly temperature in ${ }^{\circ} \mathrm{C}$, and influenza epidemics are shown in 


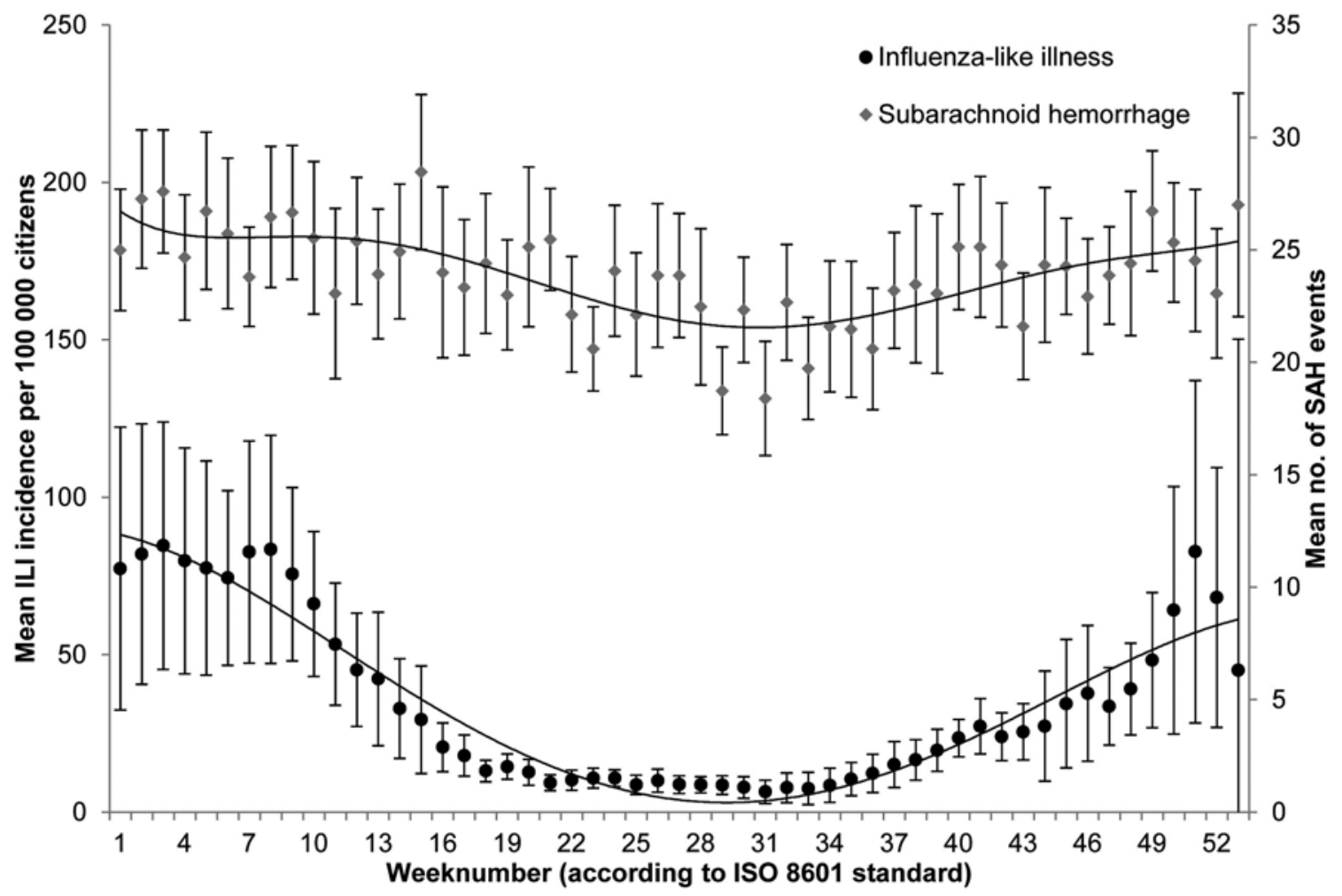

FIG. 2. Graph showing the incidence of influenza-like illness and number of SAH events per week, with corresponding $95 \% \mathrm{Cls}$ and regression trend lines for the study period October 1995 through October 2010. ILI = influenza-like illness.

Table 1. The IDR for the association between SAH and influenza epidemics was 1.021 (95\% CI 0.980-1.064) after adjustment for mean weekly temperature, and 1.030 (95\% CI 0.989-1.074) after adjustment for mean weekly temperature and study year. The IDR for SAH per $1{ }^{\circ} \mathrm{C}$ drop in mean weekly temperature was 1.004 (95\% CI 1.001-1.006) after adjustment for influenza epidemics, and 1.004 (95\% CI 1.002-1.007) after adjustment for influenza epidemics and study year.

\section{European Temperature and SAH Incidence Data}

We included SAH incidence data from 30 European population-based studies, which were included in a previous systematic review. ${ }^{9}$ These 30 studies covered 33 study periods and included populations from 12 countries. ${ }^{1-5}$ $7,8,11,17,19,21,23,25,27,29,31,39-44,46,48,49,51,53,57,59,60$ For 6 studies, data on mean daily temperature measured at weather stations closest to the geographical region in which the study was performed were imputed because of missing values $(<3 \%$

TABLE 1. Univariable (influenza epidemics or weekly temperature) and multivariable (influenza epidemics and weekly temperature) Poisson regression analyses with IDRs for SAH and corresponding $95 \% \mathrm{Cls}$

\begin{tabular}{|c|c|c|c|c|}
\hline Variable & $\begin{array}{l}\text { Univariable Model, } \\
\text { Influenza or Temperature } \\
\text { IDR }(95 \% \mathrm{Cl})\end{array}$ & $\begin{array}{c}\text { Adjusted Univariable Model, } \\
\text { Influenza or Temperature } \\
\text { alDR }(95 \% \mathrm{Cl})\end{array}$ & $\begin{array}{c}\text { Multivariable Model, } \\
\text { Influenza \& Temperature } \\
\text { IDR }(95 \% \mathrm{Cl})\end{array}$ & $\begin{array}{l}\text { Adjusted Multivariable Model, } \\
\text { Influenza \& Temperature alDR } \\
\qquad(95 \% \mathrm{Cl})\end{array}$ \\
\hline \multicolumn{5}{|c|}{ Influenza epidemics (wk) } \\
\hline Same & 1.047 (1.009-1.087) & 1.061 (1.022-1.101) & $1.021(0.980-1.064)$ & $1.030(0.989-1.074)$ \\
\hline+1 & $1.038(1.001-1.078)$ & $1.052(1.013-1.091)$ & - & - \\
\hline+2 & $1.020(0.982-1.058)$ & $1.032(0.995-1.072)$ & - & - \\
\hline+3 & $1.029(0.992-1.068)$ & $1.042(1.004-1.082)$ & - & - \\
\hline+4 & $1.021(0.983-1.059)$ & $1.033(0.996-1.073)$ & - & - \\
\hline+5 & $1.024(0.986-1.063)$ & $1.037(0.999-1.076)$ & - & - \\
\hline+6 & $1.030(0.992-1.069)$ & $1.043(1.005-1.082)$ & - & - \\
\hline+7 & $1.015(0.978-1.053)$ & $1.028(0.990-1.067)$ & - & - \\
\hline+8 & $1.014(0.977-1.053)$ & $1.027(0.989-1.066)$ & - & - \\
\hline \multicolumn{5}{|l|}{ Weekly temperature } \\
\hline Per $1^{\circ} \mathrm{C}$ decrease & $1.004(1.002-1.007)$ & 1.005 (1.003-1.008) & $1.004(1.001-1.006)$ & $1.004(1.002-1.007)$ \\
\hline
\end{tabular}

aIDR = IDR adjusted for study year; $-=$ not applicable. 


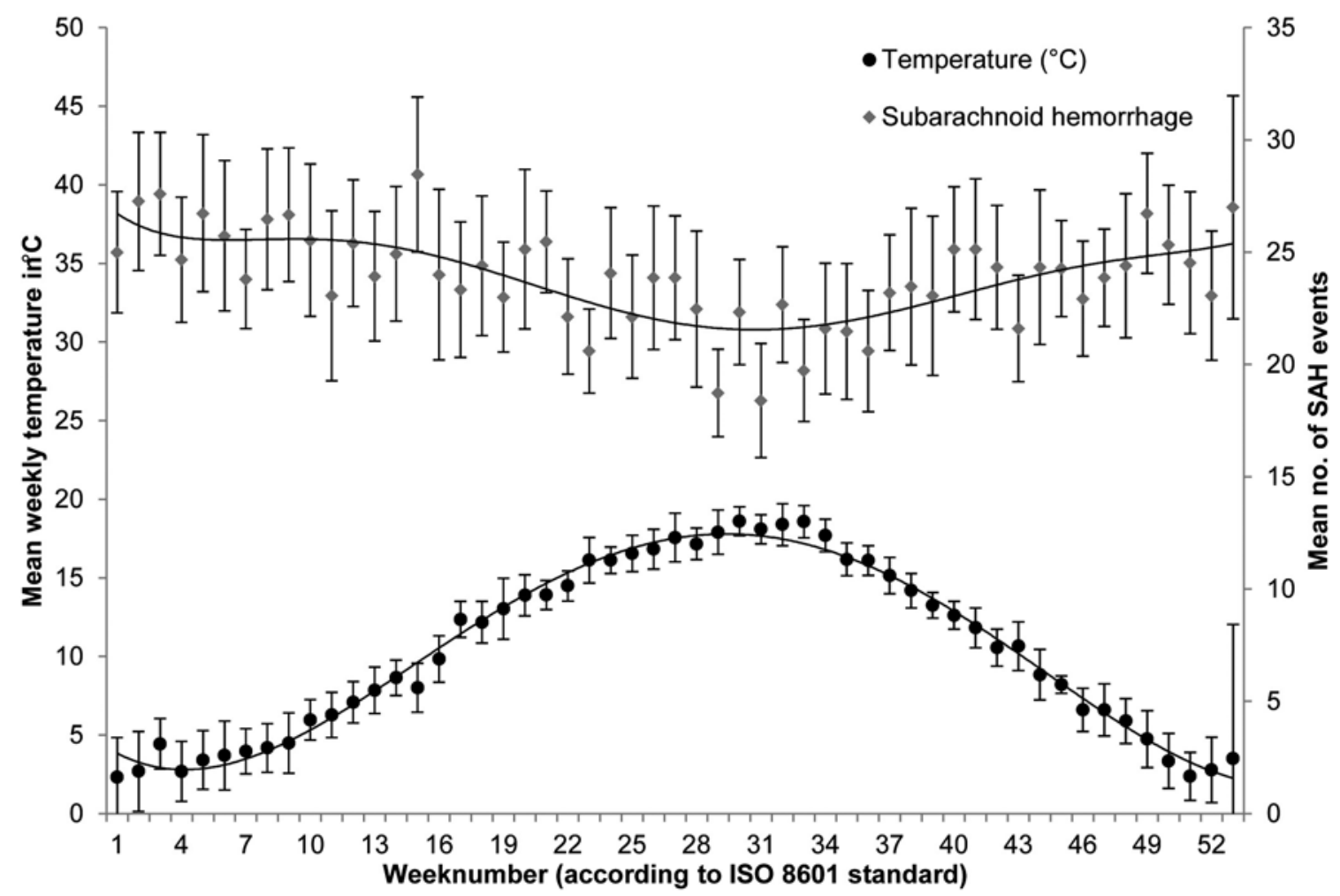

FIG. 3. Graph showing the mean weekly temperature and number of SAH events per week, with corresponding $95 \% \mathrm{Cls}$ and regression trend lines for the study period October 1995 through October 2010.

missing mean daily temperature values). ${ }^{2,3,27,42,48,53}$ For 1 study with a duration of 3 years, the mean daily temperature values of the first 2 years were used to calculate the mean temperature of the entire study period because of missing values. ${ }^{7}$ Study region, midyear of study period, number of patient-years, number of patients with SAH, SAH incidence, weather stations, and mean temperature during the study period for all included studies are shown in Table 2. The geographical regions per study are shown in Fig. 4. The IDR for the association between SAH and $1{ }^{\circ} \mathrm{C}$ drop in mean temperature during the study period was 1.143 (95\% CI 1.129-1.157).

\section{Discussion}

Our study shows a seasonal pattern in SAH incidence, with an increased SAH incidence during cold temperatures and epidemic influenza. For influenza, the association with SAH incidence gradually declines during the weeks after the start of an influenza epidemic. For temperature, cold temperatures were associated with increased SAH incidence, which was independent of the presence of influenza epidemics. The association between cold temperatures and SAH was confirmed in our analysis of 30 European population-based studies.

Previous studies from different geographical regions described associations between SAH and meteorological factors such as temperature or season, but results are conflicting. ${ }^{10,13,16,22,32,36}$ These conflicting results may be explained by referral bias or lack of power due to small sample size in single-center or small regional studies, a limited study period, or variety in study definitions (i.e., mean/ maximum/minimum temperature, temperature difference, season, or wind chill). The evidence on recent infection in relation to the incidence of $\mathrm{SAH}$ is limited. ${ }^{14,24,30,52,58}$ The results of a Canadian study from the Calgary region were comparable with our findings and showed a small but significant increase in the incidence of SAH during influenza epidemics, with a delay between increased influenza and SAH rates of 0.9 week. ${ }^{14}$

A case-control study found that an upper respiratory tract infection was an independent trigger factor for $\mathrm{SAH}$, but this study included only 44 patients. In addition, this study's retrospective design, in which patients were asked if they had infections within 4 weeks prior to hospitalization, might have led to recall bias. ${ }^{30} \mathrm{~A}$ case-crossover study on trigger factors for $\mathrm{SAH}$ found a relative risk of $2.4(95 \%$ CI 0.3-16) for flu-like illness during the 24 hours prior to SAH. ${ }^{58}$ Two other small case-control studies investigated antibody serum titers of influenza and other viral infections in patients with aneurysmal SAH. ${ }^{24,52}$ The first study showed elevated antibodies against influenza virus in patients with SAH, but the second study could not confirm these results. ${ }^{24,52}$ No study thus far has performed a multivariable analysis to examine the relationship of SAH incidence to influenza and temperature independently.

A growing body of evidence points to a key role of inflammation in the process of aneurysm rupture. ${ }^{6,54}$ Infection with the influenza virus causes an innate immune response that releases proinflammatory mediators, which lead to symptoms within 2 days. ${ }^{20,50}$ Moreover, tumor necrosis factor $-\alpha$, one of the proinflammatory mediators 
TABLE 2. Mean temperature and incidence of SAH in European population-based studies according to region and sorted by mean temperature during the study period

\begin{tabular}{|c|c|c|c|c|c|c|c|}
\hline Study Population & Region & $\begin{array}{l}\text { Midyear } \\
\text { of Study }\end{array}$ & No. of PY & $\begin{array}{l}\text { No. of } \\
\text { Pts w/ } \\
\text { SAH }\end{array}$ & $\begin{array}{c}\text { SAH } \\
\text { Incidence/100,000 } \\
\text { PY }(95 \% \text { Cl })\end{array}$ & Weather Station & $\begin{array}{c}\text { Mean } \\
\text { Temperature, } \\
{ }^{\circ} \mathrm{C}\end{array}$ \\
\hline Kuopio ${ }^{46}$ & Finland & 1979 & 159,033 & 24 & $15.1(9.1-21.1)$ & Kuopio Inkilanmaki & 0.3 \\
\hline North Karelia ${ }^{44}$ & Finland & 1984 & $1,890,000$ & 411 & $21.7(19.6-23.8)$ & $\begin{array}{l}\text { Liperi Joensuun Lentoasema \& Turku } \\
\text { Kupittaa }\end{array}$ & 2.1 \\
\hline Sweden, north ${ }^{48^{*}}$ & Sweden & 1993 & $8,212,800$ & 984 & $12.0(11.2-12.8)$ & Umea & 3.2 \\
\hline Finland ${ }^{41}$ & Finland & 1990 & 269,608 & 39 & $14.5(10.3-19.8)$ & Kuopio Kampula & 3.6 \\
\hline Söderhamn ${ }^{51}$ & Sweden & 1985 & 92,208 & 10 & $10.8(4.1-17.6)$ & Söderhamn & 3.9 \\
\hline Espoo ${ }^{41}$ & Finland & 1979 & 273,700 & 33 & $12.1(8.3-16.9)$ & Helsinki Kampula & 4.2 \\
\hline Söderhamn ${ }^{51}$ & Sweden & 1977 & 96,690 & 13 & $13.4(6.1-20.8)$ & Söderhamn & 4.3 \\
\hline Espoo-Kauniainen ${ }^{1}$ & Finland & 1972 & 107,673 & 26 & $24.1(14.9-33.4)$ & Espoo Nupuri & 5.3 \\
\hline Espoo ${ }^{41}$ & Finland & 1972 & 226,200 & 42 & $18.6(13.4-25.1)$ & Helsinki Kampula & 5.9 \\
\hline Tartu $^{57}$ & Estonia & 2000 & 101,122 & 8 & $7.9(3.4-15.6)$ & Tartu & 6.4 \\
\hline Sweden, south ${ }^{39}$ & Sweden & 1996 & $1,140,000$ & 106 & $9.3(7.6-11.2)$ & Lund & 7.3 \\
\hline Orebro $^{2 *}$ & Sweden & 1999 & 123,503 & 11 & $8.9(4.4-15.9)$ & Orebro & 7.3 \\
\hline Scotland 49 & UK & 1999 & 212,704 & 23 & $10.8(6.9-16.2)$ & Eskdalemuir & 7.8 \\
\hline Lund-Orup ${ }^{40}$ & Sweden & 1984 & 600,573 & 28 & $4.7(2.9-6.4)$ & Lund & 8.0 \\
\hline Copenhagen $^{53 *}$ & Denmark & 1984 & 295,470 & 49 & $16.6(12.3-21.9)$ & Copenhagen Landbohojskolen & 8.9 \\
\hline Malmö27* & Sweden & 1995 & $2,674,144$ & 197 & $7.4(6.4-8.5)$ & Malmö & 8.9 \\
\hline Tilburgen & Netherlands & 1979 & 302,712 & 24 & $7.9(4.8-11.1)$ & Gilze-Rijen & 9.0 \\
\hline Dijon $^{17}$ & France & 1987 & 678,560 & 15 & $2.2(1.1-3.3)$ & Langres & 9.2 \\
\hline Frederiksberg ${ }^{19}$ & Denmark & 1972 & 197,542 & 13 & $6.6(3.0-10.2)$ & Copenhagen Landbohojskolen & 9.3 \\
\hline Oxford ${ }^{3 *}$ & UK & 1984 & 420,000 & 33 & $7.9(5.2-10.5)$ & Oxford & 9.3 \\
\hline Dijon ${ }^{59}$ & France & 1996 & 429,264 & 12 & $2.8(1.4-4.9)$ & Langres & 9.5 \\
\hline Asturias $^{4}$ & Spain & 1991 & 417,033 & 28 & $6.7(4.5-9.7)$ & Oviedo & 9.6 \\
\hline Erlangen ${ }^{29}$ & Germany & 1997 & 202,900 & 12 & $5.9(3.1-10.3)$ & Nurnberg & 9.7 \\
\hline Malmö23 & Sweden & 1989 & 232,000 & 14 & $6.0(2.9-9.2)$ & Malmö & 9.9 \\
\hline London $^{60}$ & UK & 1996 & 938,132 & 74 & $7.9(6.2-9.9)$ & London & 10.1 \\
\hline Frederiksberg ${ }^{25}$ & Denmark & 1990 & 85,611 & 2 & $2.3(0.9-5.6)$ & Copenhagen Landbohojskolen & 10.5 \\
\hline Oxford 43 & UK & 2003 & 181,084 & 16 & $8.8(5.1-14.3)$ & London & 10.5 \\
\hline Valle d'Aosta ${ }^{8}$ & Italy & 1997 & 118,723 & 14 & $11.8(6.4-19.8)$ & Geneve Cointrin & 10.9 \\
\hline Portugal, north ${ }^{7 *}$ & Portugal & 1999 & 246,224 & 23 & $9.3(5.9-14.0)$ & Braganca & 12.4 \\
\hline Belluno 31 & Italy & 1992 & 211,389 & 12 & $5.7(2.9-9.9)$ & Verona Villafranca & 13.3 \\
\hline Umbria ${ }^{42 *}$ & Italy & 1988 & 147,654 & 15 & $10.2(5.0-15.3)$ & Roma Ciampino & 15.3 \\
\hline L'Aquila ${ }^{5}$ & Italy & 1994 & 297,838 & 24 & $8.0(5.2-12.0)$ & Roma Ciampino & 16.5 \\
\hline Vibo Valentia ${ }^{11}$ & Italy & 1996 & 179,186 & 12 & $6.7(3.5-11.7)$ & Brindisi & 16.5 \\
\hline
\end{tabular}

Pts = patients; $P Y=$ patient-years.

* Missing values for temperature were imputed.

released after influenza infection, is a key modulator in intracranial aneurysm formation and rupture. ${ }^{6,47}$ Another biological hypothesis for our findings is that cold temperatures cause physiological changes such as increased sympathetic nerve activity and catecholamine release. These changes lead to an increase in blood pressure, ${ }^{26,35}$ which in turn may trigger aneurysm rupture..$^{58}$

A strength of our nationwide study is that the catchment area during the study period did not change. Also, the sample size was large because we used nationwide data on the incidence of SAH and influenza-like illness. Moreover, climate differences within the Netherlands are minimal due to the relatively small surface area of approximately $41,500 \mathrm{~km}^{2}$. Another strength of our study is the use of reliable and validated registries such as the NIVEL influenza-like illness registry, the Dutch HDR and CDR, and the ECA data set of daily temperature values. . $^{12,28,33,34,38,45,56}$

Another strength of our study is the analysis, in which we used 1) population-based SAH incidence data from 12 European countries and 2) data on mean daily temperature from the ECA data set, to confirm the association between cold temperature and SAH found in our nationwide analyses. A limitation of the present study may be that we only used daily temperature data from European countries, 


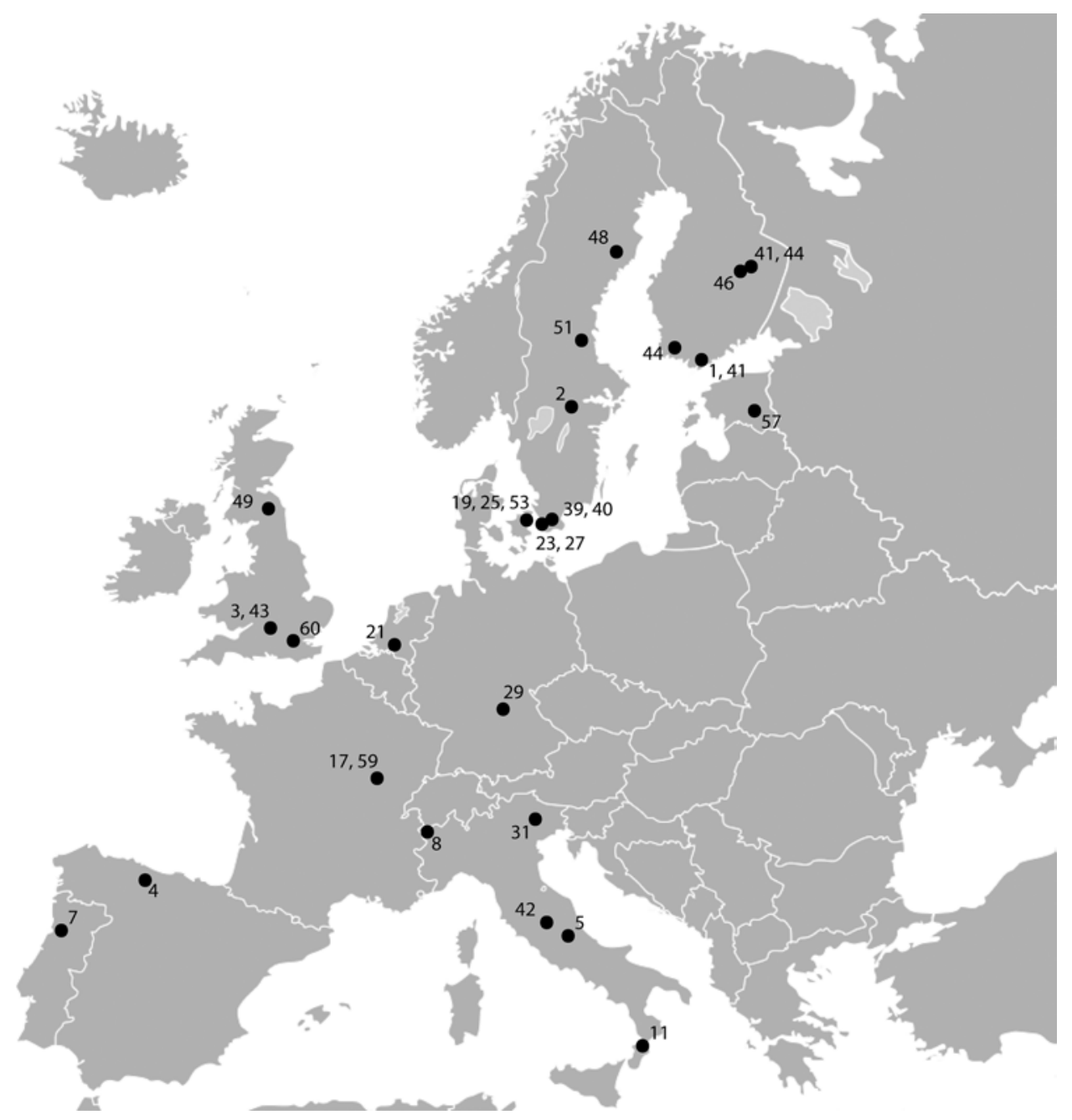

FIG. 4. Map showing the geographical regions of included population-based studies. Numbers indicate the reference number.

which might affect the generalizability of our findings to non-European populations.

Another limitation of the present study may be that we were not able to use the day of aneurysm rupture in our nationwide data set, but rather used the day of admission or death as a derivate. However, because of the acute onset of symptoms such as severe headache (often the worst headache the patient had ever experienced), loss of consciousness, neurological deficits, or vomiting, the majority of all patients with SAH present to a hospital within 24 hours after rupture. ${ }^{18}$

Another limitation is that we were not able to link data on SAH and influenza infection on an individual patient basis. Therefore, we could not adjust for well-established risk factors for SAH such as smoking status and hypertension. Moreover, we could not assess whether a causal relationship exists between occurrence of SAH and the proinflammatory immune response initiated by influenza or the physiological changes in blood pressure caused by cold temperatures. Future studies using individual patient data could shed light on a possible causal relationship between temperature or influenza and SAH.

\section{Conclusions}

Influenza epidemics and cold temperatures are associated with an increased incidence of SAH. Although the increased incidence of SAH during influenza epidemics and cold temperatures is unlikely to be caused by a single factor, our findings support the hypothesis that inflammation and physiological changes in blood pressure are contributing factors in the pathogenesis of intracranial aneurysm rupture.

\section{Acknowledgments}

This work was supported by the Ministry of Health and Sports of the Netherlands for annual surveillance activities by the Sentinel General Practice Network.

\section{References}

1. Aho K, Fogelholm R: Incidence and early prognosis of stroke in Espoo-Kauniainen area, Finland, in 1972. Stroke 5:258261, 1974

2. Appelros P, Nydevik I, Seiger A, Terént A: High incidence rates of stroke in Orebro, Sweden: Further support for region- 
al incidence differences within Scandinavia. Cerebrovasc Dis 14:161-168, 2002

3. Bamford J, Sandercock P, Dennis M, Burn J, Warlow C: A prospective study of acute cerebrovascular disease in the community: the Oxfordshire Community Stroke Project-1981-86. 2. Incidence, case fatality rates and overall outcome at one year of cerebral infarction, primary intracerebral and subarachnoid haemorrhage. J Neurol Neurosurg Psychiatry 53:16-22, 1990

4. Caicoya M, Rodríguez T, Lasheras C, Cuello R, Corrales C, Blázquez B: [Stroke incidence in Asturias, 1990-1991.] Rev Neurol 24:806-811, 1996 (Span)

5. Carolei A, Marini C, Di Napoli M, Di Gianfilippo G, Santalucia P, Baldassarre M, et al: High stroke incidence in the prospective community-based L'Aquila registry (1994-1998). First year's results. Stroke 28:2500-2506, 1997

6. Chalouhi N, Hoh BL, Hasan D: Review of cerebral aneurysm formation, growth, and rupture. Stroke 44:3613-3622, 2013

7. Correia M, Silva MR, Matos I, Magalhães R, Lopes JC, Ferro JM, et al: Prospective community-based study of stroke in Northern Portugal: incidence and case fatality in rural and urban populations. Stroke 35:2048-2053, 2004

8. D'Alessandro G, Bottacchi E, Di Giovanni M, Martinazzo C, Sironi L, Lia C, et al: Temporal trends of stroke in Valle d'Aosta, Italy. Incidence and 30-day fatality rates. Neurol Sci 21:13-18, 2000

9. de Rooij NK, Linn FH, van der Plas JA, Algra A, Rinkel GJ: Incidence of subarachnoid haemorrhage: a systematic review with emphasis on region, age, gender and time trends. J Neurol Neurosurg Psychiatry 78:1365-1372, 2007

10. de Steenhuijsen Piters WA, Algra A, van den Broek MF, Dorhout Mees SM, Rinkel GJ: Seasonal and meteorological determinants of aneurysmal subarachnoid hemorrhage: a systematic review and meta-analysis. J Neurol 260:614-619, 2013

11. Di Carlo A, Inzitari D, Galati F, Baldereschi M, Giunta V, Grillo G, et al: A prospective community-based study of stroke in Southern Italy: the Vibo Valentia incidence of stroke study (VISS). Methodology, incidence and case fatality at 28 days, 3 and 12 months. Cerebrovasc Dis 16:410-417, 2003

12. Dijkstra F, Donker GA, Wilbrink B, Van Gageldonk-Lafeber AB, Van Der Sande MA: Long time trends in influenza-like illness and associated determinants in The Netherlands. Epidemiol Infect 137:473-479, 2009

13. Feigin VL, Anderson CS, Rodgers A, Bennett DA: Subarachnoid haemorrhage occurrence exhibits a temporal pattern evidence from meta-analysis. Eur J Neurol 9:511-516, 2002

14. Field TS, Zhu H, Tarrant M, Mitchell JR, Hill MD: Relationship between supra-annual trends in influenza rates and stroke occurrence. Neuroepidemiology 23:228-235, 2004

15. Fischer T, Johnsen SP, Pedersen L, Gaist D, Sørensen HT, Rothman KJ: Seasonal variation in hospitalization and case fatality of subarachnoid hemorrhage - a nationwide danish study on 9,367 patients. Neuroepidemiology 24:32-37, 2005

16. Gill RS, Hambridge HL, Schneider EB, Hanff T, Tamargo RJ, Nyquist P: Falling temperature and colder weather are associated with an increased risk of aneurysmal subarachnoid hemorrhage. World Neurosurg 79:136-142, 2013

17. Giroud M, Milan C, Beuriat P, Gras P, Essayagh E, Arveux P, et al: Incidence and survival rates during a two-year period of intracerebral and subarachnoid haemorrhages, cortical infarcts, lacunes and transient ischaemic attacks. The Stroke Registry of Dijon: 1985-1989. Int J Epidemiol 20:892-899, 1991

18. Gould L, Petrovic R, O’Donnell MJ, Silva J, Lindsay MP, Fang J, et al: Association between time-to-presentation and clinical outcome in patients with subarachnoid hemorrhage: an observational study. Can J Neurosci Nurs 33:33-37, 2011
19. Hansen BS, Marquardsen J: Incidence of stroke in Frederiksberg, Denmark. Stroke 8:663-665, 1977

20. Hayden FG, Fritz R, Lobo MC, Alvord W, Strober W, Straus SE: Local and systemic cytokine responses during experimental human influenza A virus infection. Relation to symptom formation and host defense. J Clin Invest 101:643-649, 1998

21. Herman B, Leyten AC, van Luijk JH, Frenken CW, Op de Coul AA, Schulte BP: Epidemiology of stroke in Tilburg, the Netherlands. The population-based stroke incidence register: 2 . Incidence, initial clinical picture and medical care, and three-week case fatality. Stroke 13:629-634, 1982

22. Ishihara H, Kunitsugu I, Nomura S, Koizumi H, Yoneda H, Shirao S, et al: Seasonal variation in the incidence of aneurysmal subarachnoid hemorrhage associated with age and gender: 20-year results from the Yamaguchi cerebral aneurysm registry. Neuroepidemiology 41:7-12, 2013

23. Jerntorp P, Berglund G: Stroke registry in Malmö, Sweden. Stroke 23:357-361, 1992

24. Jones DB: An association between sub-arachnoid haemorrhage and influenza A infection. Postgrad Med J 55:853855,1979

25. Jørgensen HS, Plesner AM, Hübbe P, Larsen K: Marked increase of stroke incidence in men between 1972 and 1990 in Frederiksberg, Denmark. Stroke 23:1701-1704, 1992

26. Keatinge WR, Coleshaw SR, Cotter F, Mattock M, Murphy $\mathrm{M}$, Chelliah R: Increases in platelet and red cell counts, blood viscosity, and arterial pressure during mild surface cooling: factors in mortality from coronary and cerebral thrombosis in winter. Br Med J (Clin Res Ed) 289:1405-1408, 1984

27. Khan FA, Engstrom G, Jerntorp I, Pessah-Rasmussen H, Janzon L: Seasonal patterns of incidence and case fatality of stroke in Malmo, Sweden: the STROMA study. Neuroepidemiology 24:26-31, 2005

28. Klein Tank AMG, Wijngaard JB, Können GP, Demarée G, Gocheva A, Mileta M, et al: Daily dataset of 20th-century surface air temperature and precipitation series for the European climate assessment. Int J Climatol 22:1441-1453, 2002

29. Kolominsky-Rabas PL, Sarti C, Heuschmann PU, Graf C, Siemonsen S, Neundoerfer B, et al: A prospective community-based study of stroke in Germany-the Erlangen Stroke Project (ESPro): incidence and case fatality at 1, 3, and 12 months. Stroke 29:2501-2506, 1998

30. Kunze AK, Annecke A, Wigger F, Lichy C, Buggle F, Schnippering $\mathrm{H}$, et al: Recent infection as a risk factor for intracerebral and subarachnoid hemorrhages. Cerebrovasc Dis 10:352-358, 2000

31. Lauria G, Gentile M, Fassetta G, Casetta I, Agnoli F, Andreotta G, et al: Incidence and prognosis of stroke in the Belluno province, Italy. First-year results of a community-based study. Stroke 26:1787-1793, 1995

32. McDonald RJ, McDonald JS, Bida JP, Kallmes DF, Cloft HJ: Subarachnoid hemorrhage incidence in the United States does not vary with season or temperature. AJNR Am J Neuroradiol 33:1663-1668, 2012

33. McDonald SA, Presanis AM, De Angelis D, van der Hoek W, Hooiveld M, Donker G, et al: An evidence synthesis approach to estimating the incidence of seasonal influenza in the Netherlands. Influenza Other Respi Viruses 8:33-41, 2014

34. Merry AH, Boer JM, Schouten LJ, Feskens EJ, Verschuren WM, Gorgels AP, et al: Validity of coronary heart diseases and heart failure based on hospital discharge and mortality data in the Netherlands using the cardiovascular registry Maastricht cohort study. Eur J Epidemiol 24:237-247, 2009

35. Modesti PA, Morabito M, Bertolozzi I, Massetti L, Panci G, Lumachi C, et al: Weather-related changes in 24-hour blood pressure profile: effects of age and implications for hypertension management. Hypertension 47:155-161, 2006 
36. Neidert MC, Sprenger M, Wernli H, Burkhardt JK, Krayenbühl N, Bozinov O, et al: Meteorological influences on the incidence of aneurysmal subarachnoid hemorrhage - a single center study of 511 patients. PLoS One 8:e81621, 2013

37. Nieuwkamp DJ, Vaartjes I, Algra A, Bots ML, Rinkel GJ: Age- and gender-specific time trend in risk of death of patients admitted with aneurysmal subarachnoid hemorrhage in the Netherlands. Int J Stroke 8 (Suppl A100):90-94, 2013

38. Nieuwkamp DJ, Vaartjes I, Algra A, Rinkel GJ, Bots ML: Risk of cardiovascular events and death in the life after aneurysmal subarachnoid haemorrhage: a nationwide study. Int J Stroke 9:1090-1096, 2014

39. Nilsson OG, Lindgren A, Ståhl N, Brandt L, Säveland H: Incidence of intracerebral and subarachnoid haemorrhage in southern Sweden. J Neurol Neurosurg Psychiatry 69:601607,2000

40. Norrving B, Löwenhielm P: Epidemiology of stroke in LundOrup, Sweden, 1983-85. Incidence of first stroke and age-related changes in subtypes. Acta Neurol Scand 78:408-413, 1988

41. Numminen H, Kotila M, Waltimo O, Aho K, Kaste M: Declining incidence and mortality rates of stroke in Finland from 1972 to 1991 . Results of three population-based stroke registers. Stroke 27:1487-1491, 1996

42. Ricci S, Celani MG, La Rosa F, Vitali R, Duca E, Ferraguzzi $\mathrm{R}$, et al: A community-based study of incidence, risk factors and outcome of transient ischaemic attacks in Umbria, Italy: the SEPIVAC study. J Neurol 238:87-90, 1991

43. Rothwell PM, Coull AJ, Giles MF, Howard SC, Silver LE, Bull LM, et al: Change in stroke incidence, mortality, casefatality, severity, and risk factors in Oxfordshire, UK from 1981 to 2004 (Oxford Vascular Study). Lancet 363:19251933,2004

44. Sarti C, Tuomilehto J, Salomaa V, Sivenius J, Kaarsalo E, Narva EV, et al: Epidemiology of subarachnoid hemorrhage in Finland from 1983 to 1985. Stroke 22:848-853, 1991

45. Schlösser FJ, Vaartjes I, van der Heijden GJ, Moll FL, Verhagen $\mathrm{HJ}$, Muhs BE, et al: Mortality after elective abdominal aortic aneurysm repair. Ann Surg 251:158-164, 2010

46. Sivenius J, Heinonen OP, Pyörälä K, Salonen J, Riekkinen P: The incidence of stroke in the Kuopio area of East Finland. Stroke 16:188-192, 1985

47. Starke RM, Raper DM, Ding D, Chalouhi N, Owens GK, Hasan DM, et al: Tumor necrosis factor- $\alpha$ modulates cerebral aneurysm formation and rupture. Transl Stroke Res 5:269277, 2014

48. Stegmayr B, Eriksson M, Asplund K: Declining mortality from subarachnoid hemorrhage: changes in incidence and case fatality from 1985 through 2000. Stroke 35:2059-2063, 2004

49. Syme PD, Byrne AW, Chen R, Devenny R, Forbes JF: Community-based stroke incidence in a Scottish population: the Scottish Borders Stroke Study. Stroke 36:1837-1843, 2005

50. Temte JL, Prunuske JP: Seasonal influenza in primary care settings: review for primary care physicians. WMJ 109:193200, 2010

51. Terént A: Increasing incidence of stroke among Swedish women. Stroke 19:598-603, 1988

52. Timmons TA, Donnan GA, Whisnant JP, Shelley CD, Smith TF: Aneurysmal subarachnoid hemorrhage and viral infection. Lack of association. Arch Neurol 43:376-378, 1986

53. Truelsen T, Grønbaek M, Schnohr P, Boysen G: Stroke case fatality in Denmark from 1977 to 1992: The Copenhagen city heart study. Neuroepidemiology 21:22-27, 2002
54. Tulamo R, Frösen J, Hernesniemi J, Niemelä M: Inflammatory changes in the aneurysm wall: a review. J Neurointerv Surg 2:120-130, 2010

55. Vaartjes I, Reitsma JB, de Bruin A, Berger-van Sijl M, Bos MJ, Breteler MM, et al: Nationwide incidence of first stroke and TIA in the Netherlands. Eur J Neurol 15:1315-1323, 2008

56. van den Wijngaard CC, van Asten L, Meijer A, van Pelt W, Nagelkerke NJ, Donker GA, et al: Detection of excess influenza severity: associating respiratory hospitalization and mortality data with reports of influenza-like illness by primary care physicians. Am J Public Health 100:2248-2254, 2010

57. Vibo R, Kõrv J, Haldre S, Roose M: First-year results of the third stroke registry in Tartu, Estonia. Cerebrovasc Dis 18:227-231, 2004

58. Vlak MH, Rinkel GJ, Greebe P, van der Bom JG, Algra A: Trigger factors and their attributable risk for rupture of intracranial aneurysms: a case-crossover study. Stroke 42:18781882,2011

59. Wolfe CD, Giroud M, Kolominsky-Rabas P, Dundas R, Lemesle M, Heuschmann P, et al: Variations in stroke incidence and survival in 3 areas of Europe. Stroke 31:2074-2079, 2000

60. Wolfe CD, Rudd AG, Howard R, Coshall C, Stewart J, Lawrence $\mathrm{E}$, et al: Incidence and case fatality rates of stroke subtypes in a multiethnic population: the South London Stroke Register. J Neurol Neurosurg Psychiatry 72:211-216, 2002

\section{Disclosures}

The authors report no conflict of interest concerning the materials or methods used in this study or the findings specified in this paper.

\section{Author Contributions}

Conception and design: Backes, Rinkel, Algra, Vergouwen. Acquisition of data: Backes, Algra, Vaartjes, Donker,

Vergouwen. Analysis and interpretation of data: all authors. Drafting the article: Backes, Rinkel, Vergouwen. Critically revising the article: Rinkel, Algra, Vaartjes, Donker, Vergouwen. Reviewed submitted version of manuscript: all authors. Approved the final version of the manuscript on behalf of all authors: Backes. Statistical analysis: Backes, Algra, Vaartjes, Vergouwen. Administrative/technical/material support: Vaartjes, Donker, Vergouwen. Study supervision: Rinkel, Vergouwen.

\section{Supplemental Information}

\section{Previous Presentations}

Portions of this work were presented as an oral presentation at the European Stroke Conference, Nice, France, May 6-9, 2014, and in poster form at the European Stroke Organisation Conference, Glasgow, Scotland, April 17-19, 2015.

\section{Correspondence}

Daan Backes, Department of Neurology and Neurosurgery, Brain Center Rudolf Magnus, University Medical Center Utrecht, Rm. H02.128, PO Box 85 500, Utrecht 3500 GA, The Netherlands. email: D.Backes-2@umcutrecht.nl. 